\title{
QUALIDADE DOS RECURSOS HÍDRICOS NA COMUNIDADE FLUTUANTE LAGO DO CATALÃO, IRANDUBA - AM
}

\author{
Marcos Fabrício Leal Ramos \\ Universidade Federal do Amazonas \\ Manaus, AM \\ m.lealramos@gmail.com \\ Flávio Wachholz \\ Universidade do Estado do Amazonas \\ Manaus, AM \\ fwalemao@gmail.com \\ João Cândido André da Silva Neto \\ Universidade Federal do Amazonas \\ Manaus, AM \\ joaokandido@yahoo.com.br
}

\begin{abstract}
RESUMO
Na região amazônica existe a maior disponibilidade hídrica superficial do Brasil. Contudo parte da população não tem acesso à água tratada para o abastecimento doméstico, o qual requer certos padrões de qualidade. Neste contexto a comunidade flutuante Lago do Catalão abriga 86 famílias, onde a utilização desse recurso in natura para usos múltiplos propicia a contaminação por agentes biológicos que favorecem a proliferação de doenças de veiculação hídrica. O objetivo do trabalho foi avaliar a qualidade da água do Lago do Catalão onde se localiza a comunidade do Catalão, por meio das seguintes variáveis: coliformes fecais, temperatura, potencial hidrogeniônico $(\mathrm{pH})$, condutividade elétrica $(\mathrm{CE})$, transparência, oxigênio dissolvido (OD) e turbidez para verificar se essas estão de acordo com usos realizados pela população e legislação vigente. A metodologia consistiu na verificação dos usos da água pelos moradores através de entrevistas. Foram realizados trabalhos de campo para coleta de amostras de água in loco no período da enchente e na cheia. Portanto, de acordo com os resultados obtidos através das variáveis analisadas, a água do lago não está adequada para alguns usos realizados pela comunidade, segundo a legislação brasileira.
\end{abstract}

Palavras-chave: Usos da água. Rio Negro. Rio Solimões. Comunidade flutuante.

\section{QUALITY OF WATER RESOURCES IN THE CATALÃO LAKE FLOATING COMMUNITY, IRANDUBA-AM}

\begin{abstract}
In the Amazon region there is the greatest surface water availability in Brazil, however, part of the population does not have access to potable water for domestic supply, which requires a certain quality standards. In this context, the Catalan Lake Floating Community is home to 86 families, where the use of this natural resource may possibly to lead a contamination by biological agents that promote the proliferation of water diseases. The goal of this survey was to evaluate the water quality in the Catalan Lake, where the Catalan community is located through the water quality variables, fecal coliforms, temperature, hydrogen ionic potential (HP), electric conductivity (EC), transparency, dissolved oxygen (DO) and turbidity to check if these are in accordance with uses made by the population and current legislation. The methodology consisted in verifying the uses of water by the residents through interviews. The field work was carried out to collect water samples in loco during the flood period and when it rains a lot. Therefore, according to the results obtained through the variables analyzed, the water of the lake is not suitable for some uses carried out by the community, according to Brazilian law.
\end{abstract}

Keywords: Uses of the water. Negro River. Solimões River. Floating community.

$\begin{array}{llllll}\text { Caminhos de Geografia } & \text { Uberlândia - MG } & \text { v. 21, n. 73 } & \text { Mar/2020 } & \text { p. 98-00 } & \text { Página } 98\end{array}$




\section{INTRODUÇÃO}

A água é um recurso imprescindível para os processos urbanos, haja em vista que grande parte das atividades, sejam elas humanas ou econômicas, necessitam desse recurso. Contudo a ação do homem nas bacias hidrográficas tem interferido nos ecossistemas aquáticos e levado à perda qualitativa e quantitativa da água.

Estudos de qualidade da água tornam-se indispensáveis para conservação e manutenção dos recursos hídricos, pois possibilita ações e estratégias que visam o controle de qualidade da água e conservação desse recurso que é determinante para organização da sociedade, visto que a água é um bem fundamental para a manutenção da vida.

O déficit hídrico é cada vez mais frequente, ocasionando um problema a nível mundial. Isso porque a água potável, cujos parâmetros microbiológicos, físicos e químicos atendam parcialmente sem tratamento prévio ao padrão de potabilidade, está contida nas calotas polares e nas geleiras, que armazenam $2 \%$ da água do planeta, e apenas $1 \%$ dessa está nos lençóis subterrâneos, lagos e rios (PEIXOTO FILHO e BONDAROVSKY, 2000).

A distribuição de água doce no Brasil é desigual, pois existem regiões que possuem excedente hídrico de águas superficiais e outras que possuem déficit (TUNDISI e MATSUMURA TUNDISI, 2008).

A região Amazônica é um incomparável repositório de águas doces situadas na faixa equatorial. Nessa bacia estão dispostos lagos de várzea, os furos, os paranás e os igapós, quadro hidrográfico característico da região, que possui um regime hidrológico que altera o volume de suas águas a cada seis meses, ocasionado por uma grande diversidade climatológica da região (MORAES, 1960).

A região Norte, neste contexto, tem uma posição privilegiada no que diz respeito à disponibilidade de água in natura, pois aproximadamente $70 \%$ da disponibilidade hídrica do Brasil se encontra nessa região, onde vive apenas $7 \%$ da população do país. As demais regiões que abrigam o restante da população dispõem apenas de 30\% da disponibilidade hídrica brasileira (MACHADO, 2003).

Contudo, Lima et al. (2011) afirmam que a disponibilidade hídrica do Amazonas entre 1980 a 2007 reduziu cerca de $46 \%$. As principais razões que corroboram para esse decréscimo é a crescente degradação do meio hídrico, o aumento da população urbana e a ineficácia na distribuição por parte dos sistemas de abastecimento.

Para Melo et al. (2005), o elevado crescimento na degradação dos recursos hídricos, destacando os efluentes domésticos é um dos principais fatores do decréscimo qualitativo. Nesse sentido, Tucci (2008) afirma que o Brasil, mesmo com todos os avanços na legislação nacional nas últimas décadas, ainda está na fase higienista, devido à falta de tratamento de efluentes em quase todos os meios urbanos do país. $O$ reflexo dessa problemática é a ineficiência dos sistemas de tratamento e distribuição de água no Brasil.

Segundo Machado (2003), o país tem um alto índice de desperdício, em média entre 40 a $60 \%$ da água tratada e pronta para o consumo humano é perdida no percurso entre a captação até sua distribuição nas torneiras dos domicílios. O principal fator contribuinte para esse desperdício é a falta de estrutura na distribuição e a utilização de tecnologias obsoletas, tubulações antigas, vazamentos, desvios clandestinos que com o aumento demográfico, o desenvolvimento industrial e a ocupação desordenada e de maneira irregular do solo causam impactos diretos no meio ambiente aquático, diminuindo drasticamente a qualidade desse serviço.

Além disso, o abastecimento de água tem uma ligação intrínseca com o conceito de limpeza, com as políticas de saneamento e de meio ambiente. Em países subdesenvolvidos as cidades possuem fases de desenvolvimento do sistema de água urbana em vários estágios. Nas cidades brasileiras, especialmente na região Norte, a maioria sequer chegou à fase higienista, tendo assim, todos seus efluentes urbanos lançados diretamente nos corpos d'água sem nenhum tratamento (TUCCI, 2008).

De acordo com Sarri (2018) os recursos hídricos, historicamente, são utilizados para despejo indiscriminado de resíduos e depuração de efluentes, sejam eles nas áreas urbanas ou rurais. Essa prática rudimentar traz como consequência significativa degradação ambiental dos ecossistemas aquáticos, pois os efluentes líquidos lançados diretamente nos recursos hídricos são considerados uma

\begin{tabular}{llllll}
\hline Caminhos de Geografia & Uberlândia - MG & v. 21, n. 73 & Mar/2020 & p. 98 - 115 & Página 99
\end{tabular}


problemática mundial, principalmente pela falta de tecnologias que possibilitem o tratamento e a disposição final ambientalmente adequada.

Tucci (2001) realça que no Brasil o abastecimento de água não deveria ser um problema, pois existe grande disponibilidade hídrica que permitiria boa cobertura desse serviço em todo o território, contudo a contaminação dos mananciais em virtude da quase inexistente cobertura de redes de tratamento de efluentes faz com que essa disponibilidade seja afetada por um ciclo de contaminação. Esse que é produzido pelo intenso volume de efluentes não tratados lançados nos corpos d'água, o resultado desse ciclo é a diminuição direta da qualidade da água para o abastecimento que impacta também na saúde pública.

Desse modo, o meio aquático tem se destacado por sua importância para a vida não somente por ser vital à sobrevivência, mas também pelo seu uso na navegação, irrigação, pesca e consumo doméstico e industrial.

O lançamento de efluentes líquidos, sejam eles domésticos ou industriais, nos corpos hídricos provocam alterações físicas, químicas e biológicas, causando malefícios, degradando os ecossistemas aquáticos. O esgotamento doméstico e industrial são as principais causas da contaminação dos recursos hídricos, se transformando num grande desafio, qual seja a criação de alternativas para mitigação da degradação ambiental, principalmente em áreas que não possuem rede coletora de esgoto e sistema convencional de tratamento. Nas áreas rurais, especialmente as da região Norte do país, a escassez de tecnologias de baixo custo, que atendam ao contexto local e que possam substituir os lançamentos diretos nos rios e lagos é um significativo problema ambiental, nas grandes cidades. O crescimento populacional desordenado também contribui para a falta de saneamento, sobretudo a falta de rede coletora e tratamento adequado do esgoto (SARRI, 2018).

No Brasil apenas 50,3\% da população tem acesso à coleta de esgoto, ou seja, mais de 100 milhões de habitantes não têm acesso a este serviço básico. Levando em consideração as 100 maiores cidades brasileiras, mais de 3,5 milhões de brasileiros despejam seu esgoto de forma irregular, mesmo tendo a rede coletora passando em frente a suas residências (INSTITUTO TRATA BRASIL, 2018).

Nesse sentido a água é o recurso natural de notável importância para a manutenção da vida, participando e dinamizando todos os ciclos ecológicos. Os sistemas aquáticos nesse processo têm enorme importância, pois a diversidade de espécies por esse proporcionadas é de utilidade humana (alimentação) e também parte ativa e relevante dos ciclos biogeoquímicos e da diversidade biológica do planeta Terra (TUNDISI, 2003).

Embora na natureza esse bem se encontre em enorme proporção, suas condições são impróprias para o consumo direto e sem tratamento. Mais de $97 \%$ da água do planeta é salgada, logo dispomos apenas de $3 \%$ de água doce no planeta para os mais diversos usos, sejam esses industriais ou domésticos. Dessa pequena porcentagem a maior parte está contida em geleiras ou acumulada em lençóis subterrâneos, restando menos de $1 \%$ de água doce disponível na superfície pronta para o uso humano (ASSIS, 1998). Ainda falando a respeito da disponibilidade a nível global, Tundisi (2003) também afirma que no planeta Terra a maior parcela desse recurso encontra-se nos oceanos, logo essas são salobras e improprias para ser utilizada para irrigação, uso doméstico e dessendentação, restando então apenas uma pequena porção, aproximadamente algo em torno de 35 milhões de quilômetros cúbicos, onde a maior parte desse volume está no estado sólido sob forma de gelo na Antártida ou na Groenlândia.

Os usos da água são diversos, como abastecimento doméstico, abastecimento industrial, agricultura, recreação e lazer, harmonia paisagística e preservação da fauna e flora (MARENGO, 2008). Esses usos múltiplos da água pelas atividades humanas possuem consequências sobre o corpo d'água. Dependendo da finalidade, esses efeitos para o meio ambiente podem ser positivos ou negativos. $O$ uso dos recursos hídricos, além dos já mencionados pode ser destinado também para a geração hidrelétrica, navegação fluvial e pesca. Esses usos são básicos para o consumo e manutenção da vida social e dependem diretamente do meio ambiente aquático preservado para que se possa dispor do mesmo, logo é notável que esse elemento possua enorme valor para o desenvolvimento social e econômico das populações. No entanto a crescente modificação desse meio natural pelas ações antrópicas tem ocasionado à diminuição de sua qualidade e disponibilidade que afeta diretamente o bem-estar social e econômico (LIBÂNIO et al, 2005).

\begin{tabular}{llllll}
\hline Caminhos de Geografia & Uberlândia - MG & v. 21, n. 73 & Mar/2020 & p. 98 - 115 & Página 100
\end{tabular}


O uso da água pode ser mais ou menos consuntivo, isto é, pode resultar em perda elevada, média ou reduzida de água. A perda é a diferença entre o volume de água retirado do corpo d'água para ser utilizado e o volume devolvido, ao final do uso, ao mesmo corpo d'água. No abastecimento urbano, descontadas as perdas pela rede de distribuição, o uso consuntivo pode ser considerado baixo, em torno de $10 \%$. Todavia, no abastecimento industrial, o uso consuntivo varia conforme o setor, situando-se em torno de $20 \%$. Na irrigação, o uso consuntivo é elevado, alcançando $90 \%$. Por outro lado, na geração de energia elétrica a perda é, em geral, baixa e se dá somente pela evaporação (BORSOI e TORRES, 1997, p. 3).

Nesse contexto, a comunidade flutuante lago do Catalão, localizada nos furos dispostos na planície de inundação de confluência dos rios Negro e Solimões, possui visivelmente uma ótima disponibilidade hídrica superficial, mas sem tratamento para o consumo. É importante realçar que a comunidade não possui rede de esgoto cloacal, sendo todos os efluentes domésticos produzidos lançados diretamente no corpo hídrico. Essa condição propicia o aumento da contaminação por agentes biológicos oriundo dos efluentes, o que favorece a proliferação de doenças de veiculação hídrica, tornando assim esse meio possivelmente fora dos padrões de qualidade exigidos pela legislação brasileira.

Devido à falta de abastecimento de água potável, os moradores são obrigados a buscar outras fontes para sanar a necessidade desse recurso para o consumo humano. Para atender às suas necessidades domésticas e de higiene pessoal são utilizadas as águas do Lago do Catalão. Esse corpo hídrico é também um importante meio de locomoção dos moradores, servindo ainda como fonte de renda para boa parte da população residente através da pesca e atividades turísticas.

Deste modo, o presente artigo teve por objetivo geral analisar a qualidade da água do Lago do Catalão, em diferentes períodos hidrológicos, associando aos referentes usos.

\section{METODOLOGIA}

\section{CARACTERÍSTICAS DA ÁREA DE ESTUDO}

O Lago do catalão localiza-se na planície de inundação do rio Negro em confluência com o rio Solimões, fazendo parte do município de Iranduba, no estado do Amazonas (Amazônia Central) (Figura 1). Essa área contempla um lago ligado aos rios mencionados, a aproximadamente $3 \mathrm{~km}$ do porto da Ceasa na cidade de Manaus (LEITE et al., 2006). No lago situa-se a comunidade flutuante que abriga 85 famílias, que estão localizadas nos furos 1 e 2 que ligam o lago ao rio Negro (figura 2).

A topografia da área é uniforme e plana, devido a acumulação fluvial, sendo formada pelos domínios da província de depósitos Cenozóicos, constituída por sedimentos quaternários representados por aluviões de origem holocênicas, apresentando altitudes que raramente superam os 100 metros. Como principal característica a região possui terras baixas contendo uma cadeia de lagos próximo ou ligados uns aos outros, que de acordo com a variação sazonal do nível das águas esses podem alagar totalmente ou secar completamente (BRITO, 2006).

O lago tem como característica latente a entrada de solutos do rio Negro e Solimões, que condicionam o pulso de inundação. Desse modo é de se esperar que o balanço hidrológico do lago seja intimamente influenciado por esses dois corpos hídricos, rio Negro e rio Solimões, que caracterizam o lago como uma mistura variável dessas duas grandes fontes hídricas distintas quimicamente (ALMEIDA, 2008). O pulso de inundação apresenta maior contribuição do rio Negro em quase todos os períodos hidrológicos. Por outro lado, o rio Solimões, no período de cheia é capaz de subir o suficiente para transpor a região de várzea e influenciar de maneira direta as características hidrológicas do lago (ALMEIDA e MELO, 2009). 
Figura 1 - Mapa da área de estudos.
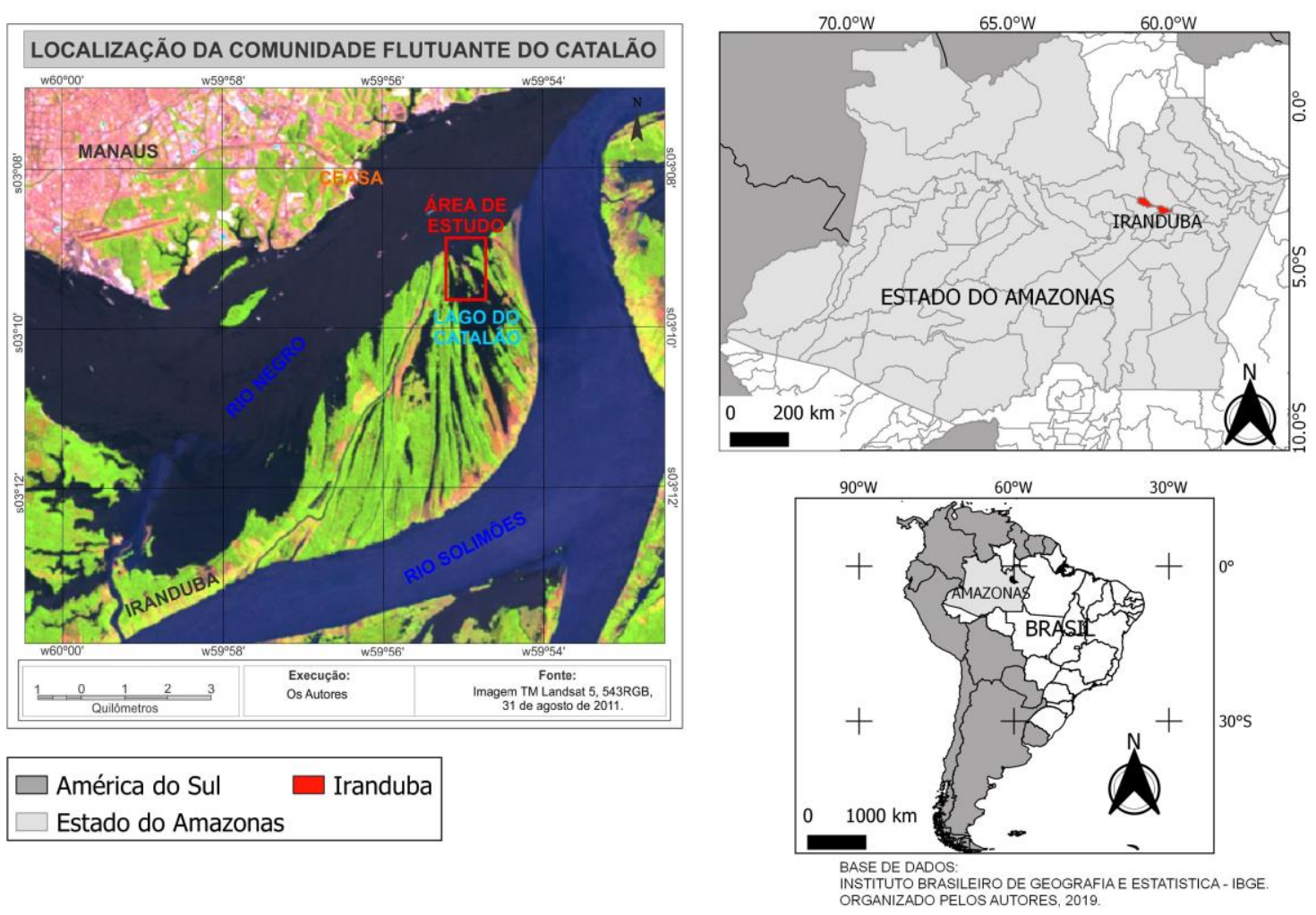

Organização: Autores, 2019.

Figura 2 - Entrada da comunidade.

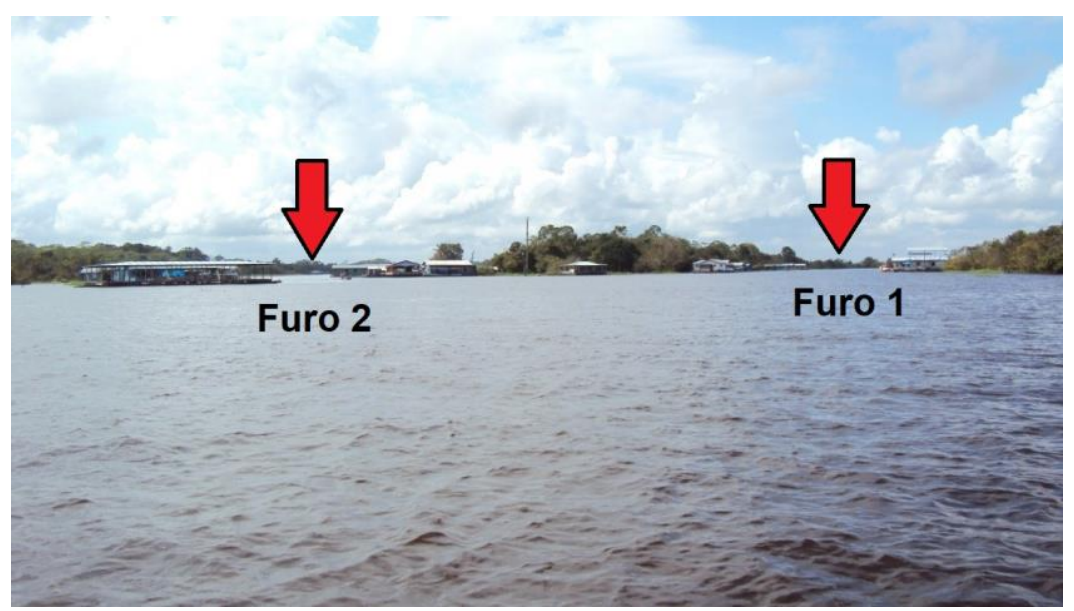

Fonte: RAMOS e WACHHOLZ, 2017.

Segundo Bleich et al. (2014) no lago são encontrados, além de águas pretas, ambientes de água branca, água branca decantada, e água mista. Logo a diferença hídrica na região promove alteração das características físico-químicas naturais e principalmente na coloração da água. Isso ocorre principalmente pela diferença de velocidade, pela decantação e misturas de águas dos rios Solimões (águas brancas) e Negro (águas pretas).

Nesse contexto, essa região possui grande diversidade de ambientes aquáticos, reunidos na mesma bacia hidrográfica, porém com estruturas geológicas diferentes, refletindo em variados tipos de águas (SIOLI, 1985). Esses tipos de água possuem propriedades físicas e químicas que apresentam algumas peculiaridades que as diferenciam de outras águas das diversas regiões do país que dificulta a elaboração de normas que possam ser aplicadas indistintamente a todos os ambientes aquáticos. É o caso da

$\begin{array}{llllll}\text { Caminhos de Geografia } & \text { Uberlândia - MG } & \text { v. 21, n. 73 } & \text { Mar/2020 } & \text { p. 98-115 Página } 102\end{array}$


Resolução Conama №. 357/2005. Nesse sentido essa poderá até ser aplicada nessa região, mas não deixará de haver dificuldades para conciliar alguns requisitos contidos na mesma com os que apresentam os ambientes naturais amazônicos (SANTOS, 2014).

\section{PROCEDIMENTOS METODOLÓGICOS}

A definição da metodologia ocorreu inicialmente com a visualização das imagens de satélite disponíveis no Google Earth, que foram utilizadas para delimitar a área de estudo e determinar uma prévia distribuição dos pontos amostrais para coleta de dados.

O reconhecimento da área de estudo foi realizado no dia 12 de janeiro de 2014 com apresentação do projeto de pesquisa à presidente da comunidade, e após ocorreu um diálogo para obter dados referentes à comunidade. A segunda visita à comunidade, no dia 23 de fevereiro de 2014, teve por objetivo a definição da quantidade e localização dos pontos amostrais de acordo com a distribuição espacial das moradias flutuantes e o despejo de efluente.

Com base nessas informações e com o uso das imagens do Google Earth os pontos amostrais foram definidos. Porém o deslocamento de alguns pontos foi necessário no primeiro campo de coleta de água, em função do nível do lago e da distribuição atual de moradias, haja vista que essas estão em constante movimento de acordo com a sazonalidade do lago.

Sendo assim foram definidos 15 pontos amostrais (figura 3) para medir as variáveis e para a coleta de água, sendo os pontos de 1 a 6 correspondente ao furo 1 da comunidade, este que possui extensão de 395 metros, e os pontos de 7 a 14 correspondente ao furo 2, com extensão de 925 metros. O ponto 15 foi amostrado na entrada da comunidade, e no período hidrológico de cheia foi coletado o ponto 16 no rio Negro para fins de comparação.

Para a locomoção entre Manaus e a área de estudo foi utilizada uma voadeira de pequeno porte (motor de poupa $15 \mathrm{HP}$ ), em virtude da distância de $3 \mathrm{~km}$ entre o porto da Ceasa em Manaus até a comunidade flutuante Lago do Catalão, sendo o tempo de deslocamento de 15 a 20 minutos.

A coleta de dados foi realizada em dois períodos hidrológicos: na enchente (27 de dezembro de 2014) e na cheia (15 de julho de 2015). As coletas foram realizadas entre 9 e 11 horas.

No período hidrológico da enchente o trabalho de campo foi realizado quando o rio Negro apresentava cota de 21,54 m, na cheia o mesmo se realizou quando o rio Negro se encontrava com 29,39 m, próximo a sua cota máxima 29,66 m, 29 de junho de 2015 (Porto de Manaus, 2015).

Segundo Bittencourt e Amadio (2007) a variabilidade do rio Negro e do rio Solimões, localizados nas proximidades da cidade de Manaus, possuem sazonalidades que afetam diretamente as regiões de seu entorno, neste caso o Lago do Catalão. Ainda de acordo com esses autores os quatro períodos hidrológicos são definidos da seguinte forma: enchente (janeiro a abril) quando o rio Negro se encontra ascendente entre 20 a 26 metros; cheia (maio a julho) com nível do rio superior 26 metros; vazante (agosto a setembro) com nível do rio descendente entre 26 a 20 metros; seca (outubro a dezembro) quando o nível for inferior a 20 metros. Logo, o recorte temporal dessa pesquisa contempla dois períodos hidrológicos distintos.

As variáveis limnológicas medidas in situ foram: temperatura da água $\left({ }^{\circ} \mathrm{C}\right)$ e transparência $(\mathrm{cm})$. A temperatura da água foi medida com termômetro digital portátil (Tipo Espeto Instrutherm - TE 400) com resolução de $0,1^{\circ} \mathrm{C}$ e precisão de $0,5^{\circ} \mathrm{C}$. A transparência foi medida com disco de Secchi de $30 \mathrm{~cm}$ de diâmetro, no qual a leitura é indicada pelo desaparecimento na coluna d'água e realizada por um único observador.

Para as variáveis condutividade elétrica, $\mathrm{pH}$, turbidez (NTU) e oxigênio dissolvido (mg/L), as amostras foram coletadas em frascos plásticos (garrafas PET de polietileno) de acordo com a Associação Brasileira de Normas Técnicas (ABNT, 1987) e Preservação e técnicas de amostragem de efluentes líquidos e corpos receptores e pelo guia nacional de coleta e preservação de amostras (CETESB, 2011). 
Figura 3 - Pontos amostrais.

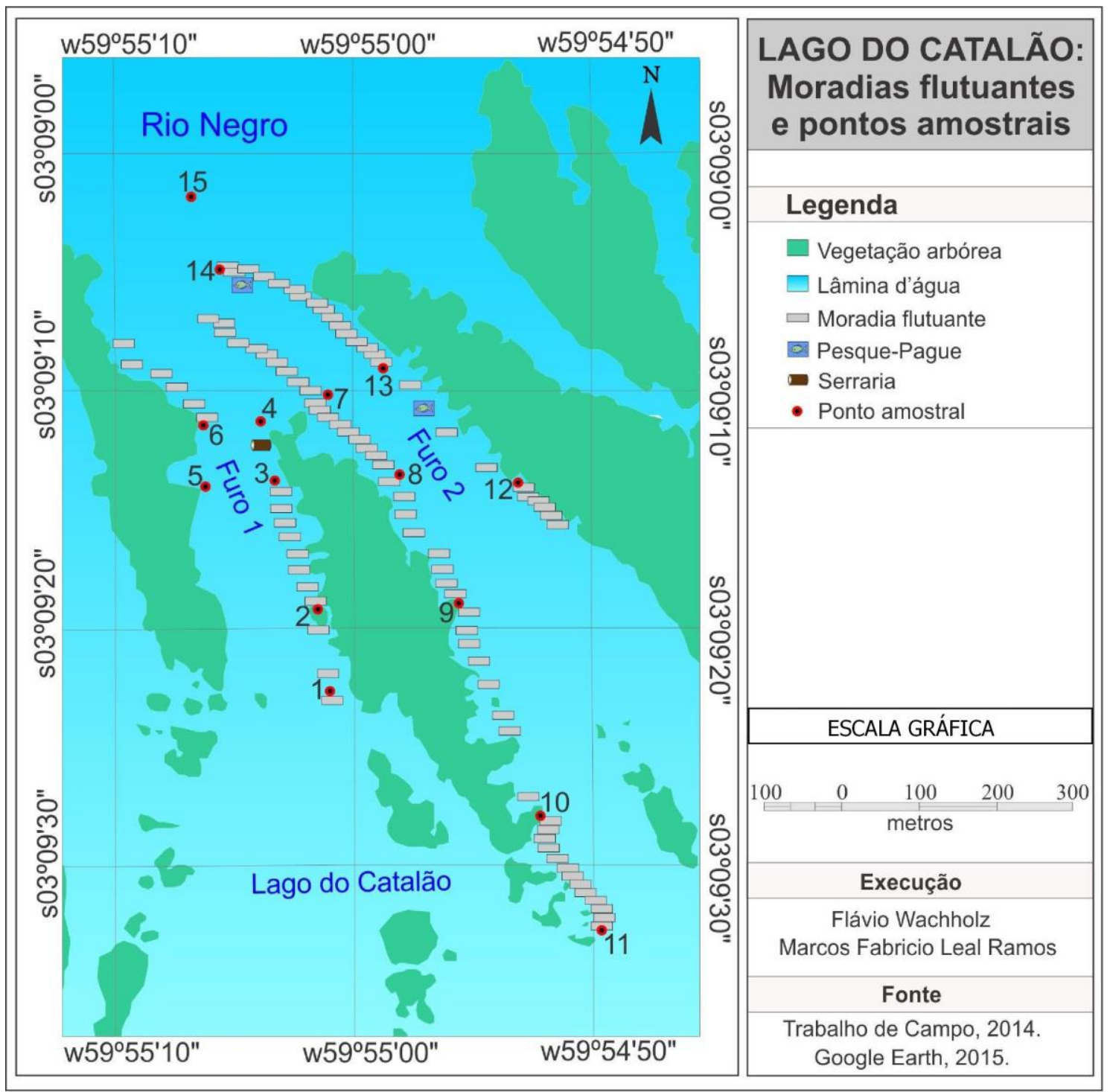

Organização: Autores, 2019.

O equipamento multiparâmetro de bancada Hanna® Edge foi utilizado para medir o pH (Resolução 0,01 e precisão $\pm 0,01$ ), condutividade elétrica em $\mu \mathrm{S} / \mathrm{cm}$ (Resolução 0,1 e precisão de $\pm 1 \%$ de leitura) e o oxigênio dissolvido em $\mathrm{mg} / \mathrm{L}$ (Resolução 0,01 e precisão de $\pm 1,5 \%$ de leitura).

O Turbidímetro digital portátil (Instrutherm TD-300) foi utilizado para medir a turbidez em NTU (Resolução 0,01 e precisão de $\pm 0,5 \mathrm{NTU}$ ).

A variável coliformes fecais foi amostrada apenas em um período hidrológico (cheia). Essa foi analisada em laboratório com a utilização do kit Aquateste coli, meio de cultura destinado à detecção quantitativa e qualitativa de coliformes totais e Escherichia coli (E. coli) na água. Cabe realçar que essa variável juntamente com a condutividade elétrica, $\mathrm{pH}$, turbidez e oxigênio dissolvido foram analisadas no laboratório de química, Universidade do Estado do Amazonas (UEA), Escola Superior de Tecnologia (EST).

O kit Aquateste compreende os bacilos gram negativos fermentadores de lactose e compreendendo os gêneros Escherichia, Citrobacter, Enterobacter e Klebisiella. É um meio em pó, composto por nutrientes, ONPG (ortonitrofenol-beta-galacto-piranosideo) e MUG (methyl-umbelipheril-glucuronide) apresentado em frascos para diluir $100 \mathrm{~mL}$ de amostra.

Para as análises tomou-se como base a Portaria № 2.914/2011, pois essa enquadra águas in natura, quando são destinadas ao abastecimento humano como fonte alternativa. A análise dos resultados de

$\begin{array}{llllll}\text { Caminhos de Geografia } & \text { Uberlândia - MG } & \text { v. 21, n. } 73 & \text { Mar/2020 } & \text { p. } 98 \text { - } 115 & \text { Página } 104\end{array}$


coliformes totais e E. coli teve como base o anexo XI (que dispõe sobre o padrão microbiológico para água potável). Segundo o parágrafo 30 da Portaria №. 518/2004, todas as amostras com resultados positivos para coliformes totais devem ser analisadas para E. coli para obter a verificação e confirmação dos resultados positivos para contaminação fecal (BRASIL, 2011).

Para isso foi utilizada a técnica dos tubos múltiplos, conforme prevê a metodologia prevista no kit. Os procedimentos realizados em laboratório foram os seguintes:

1. Inicialmente foram retirados $100 \mathrm{~mL}$ de água coletada in loco, onde esse volume foi obtido por meio de uma proveta graduada.

2. Cada amostra $(100 \mathrm{~mL})$ foi disposta em béquer $(200 \mathrm{~mL})$, um para cada ponto de amostragem, logo um total de 16.

3. Posteriormente foi adicionado o meio (Aquateste coli) e em seguida foi realizado a homogeneização desse meio com o bastão de vidro e agitando suavemente o frasco.

4. Após a homogeneização o conteúdo de cada béquer foi divido em 5 tubos de ensaio estéreis (que não emitam fluorescência quando expostos à luz ultravioleta) contendo $20 \mathrm{~mL}$ do total homogeneizado (100 $\mathrm{mL}$ ). Esse procedimento foi realizado com uma pipeta graduada.

5. Em seguida os 80 tubos (5 de cada ponto de amostragem) foram organizados em duas estantes de plástico devidamente identificadas separando as amostras do furo 1 e 2 .

6. Após a identificação as estantes foram incubadas em estufa bacteriológica por 20 horas (segundo o kit o ideal é entre 18 a 24 horas) a $35^{ \pm} 2^{\circ} \mathrm{C}$.

7. Por fim após a retirada das amostras da estufa foi realizada visualmente a identificação por contaminação coliforme totais, pois desenvolve coloração amarelada (figura 4), e em seguida os tubos foram expostos à luz ultravioleta de $366 \mathrm{~nm}$ (lanterna para fluorescência CIELAB, modelo UV- LAMP) para verificação da contaminação por $\mathrm{E}$. Coli, uma vez que essa emite fluorescência quando em exposição a essa luminosidade, conforme figura 5.

Figura 4 - Prova positiva para contaminação por coliformes totais, coloração amarela.

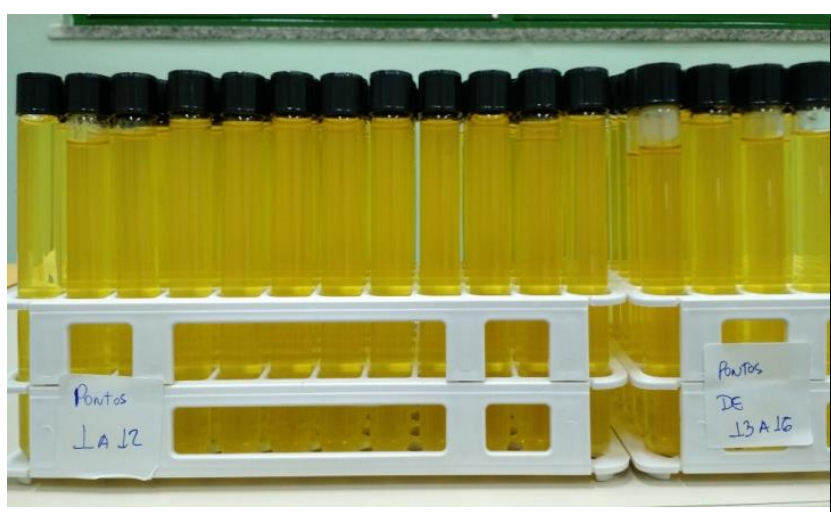

Fonte: RAMOS, Marcos Fabricio Leal, 2015.
Figura 5 - Prova positiva de contaminação por Escherichia coli, fluorescência.

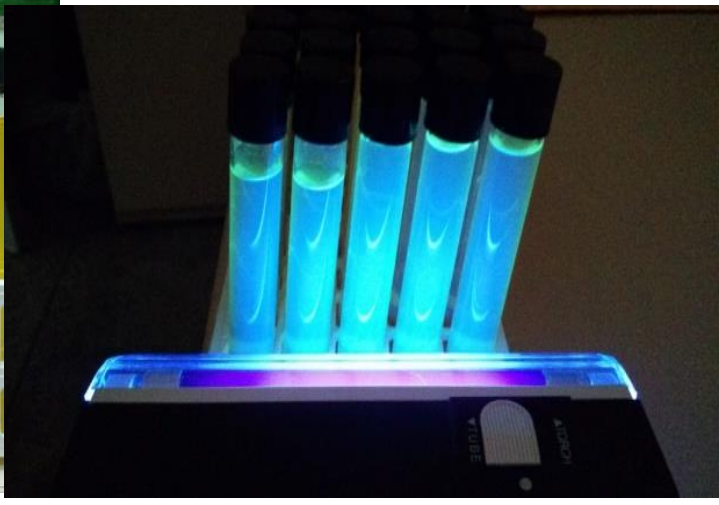

Em relação aos valores quantitativos consideram-se contagens de coliformes com NMP (número mais provável), onde valores inferiores a $1,1 / 100 \mathrm{~mL}$ são aceitáveis para o consumo humano, conforme tabela 1. 
Tabela 1 - Valores de número mais aproximado (NMP)*.

\begin{tabular}{c|c|c}
\hline $\begin{array}{c}\text { Tubos positivos } \\
\text { (Coliformes totais e Escherichia } \\
\text { coli) }\end{array}$ & NMP/100 $\mathbf{~ L L}$ & $\begin{array}{c}\text { Definição para o } \\
\text { consumo }\end{array}$ \\
\hline 0 & $<1,1$ & Aceitável \\
1 & 1,1 & Inadequado \\
2 & 2,6 & Inadequado \\
3 & 4,6 & Inadequado \\
4 & 8 & Inadequado \\
5 & $>8,0$ & Inadequado \\
\hline
\end{tabular}

* Valores obtidos no manual do kit Aquateste Coli.

Fonte: Laborclin, 2015.

Elaboração: RAMOS, Marcos Fabricio Leal, 2015.

Os usos da água do lago, segundo a legislação Conama №. 357/2005 são de dois tipos, de contato primário e secundário. Os contatos primários são aqueles que ocorrem quando a possibilidade do usuário de ingerir água é elevada (escovar os dentes, tomar banho, natação, dessedentação animal). Enquanto os usos de contato secundário ocorrem quando a possibilidade de ingerir água é pequena, esporádica ou acidental (pescar, lavar louça/roupa, irrigação e navegação), conforme o quadro 1.

Quadro 1 - Enquadramento dos usos perante a Resolução.

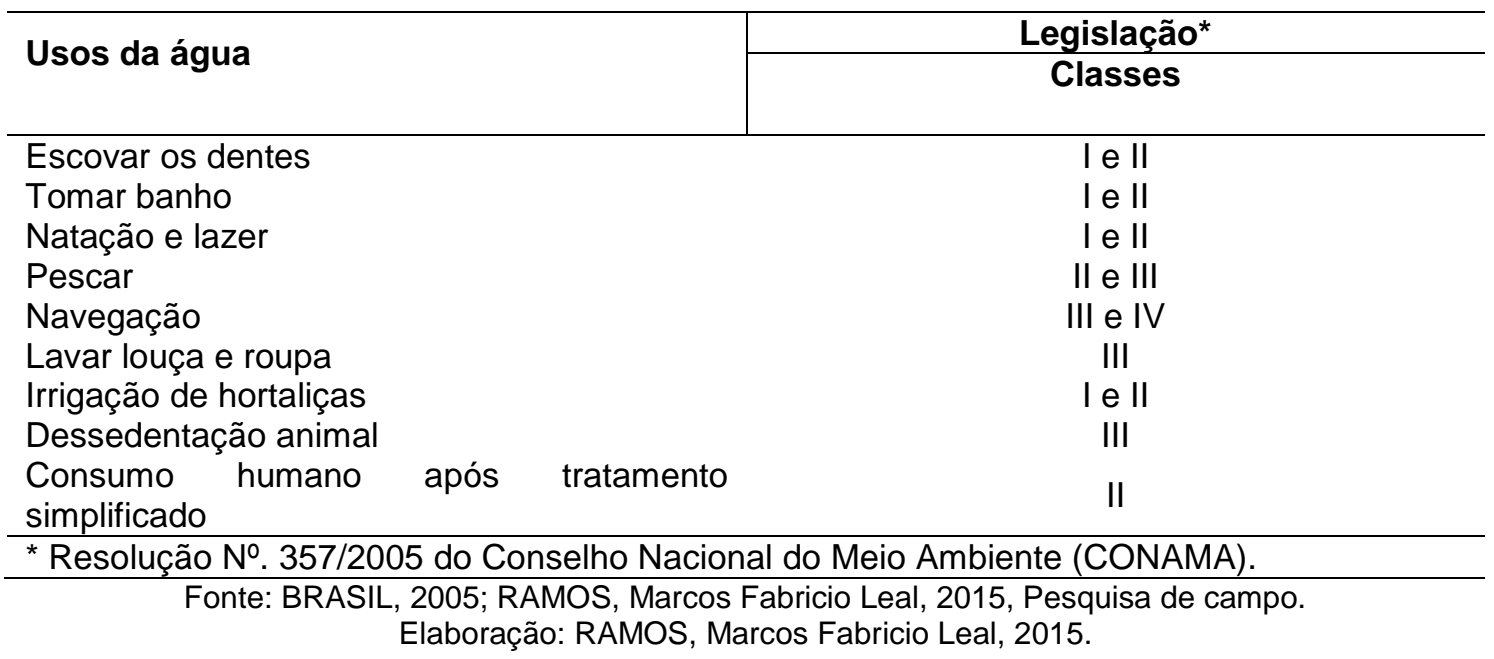

Essa resolução para assegurar os usos promove a classificação das águas considerando condições e padrões específicos que visa à defesa de seus níveis de qualidade. A água in natura para que esteja de acordo com o estabelecido por essas classes deve apresentar determinados padrões nas mais diversas variáveis, nessa pesquisa as seguintes variáveis estão contempladas na legislação, conforme a tabela 2. 
Qualidade dos recursos hídricos na comunidade flutuante Lago do Catalão, Iranduba - AM

Tabela 2 - Valores de enquadramento das classes.

\begin{tabular}{|c|c|c|c|c|c|}
\hline \multirow{2}{*}{ Variáveis } & \multicolumn{5}{|l|}{ Classes* } \\
\hline & Especial & I & II & III & IV \\
\hline Oxigênio dissolvido (mg/L) & $>10$ & 10 a 6 & 6 a 5 & 5 a 4 & $<4$ \\
\hline $\mathrm{pH}$ & 6 a 9 & 6 a 9 & 6 a 9 & 6 a 9 & 6 a 9 \\
\hline Turbidez (NTU) & Até 20 & 20 a 40 & 40 a 70 & $\begin{array}{ll}70 & a \\
100 & \end{array}$ & $>100$ \\
\hline
\end{tabular}

${ }^{\star}$ Especial - consumo humano e preservação das comunidades aquáticas. I - Consumo humano (tratamento simplificado), recreação e irrigação. II - Consumo humano (tratamento convencional), recreação, irrigação e atividade de pesca. III - consumo humano (convencional ou avançado), irrigação (culturas arbóreas), pesca amadora e dessedentação animal. IV - Navegação e à harmonia paisagística.

Fonte: Lelis e Pinto, 2014.

Elaboração: RAMOS, Marcos Fabricio Leal, 2015.

\section{RESULTADOS E DISCUSSÃO}

A coloração da água dos dois furos se apresentou preta na enchente e branca na cheia, essa diferença se deve pela influência do pulso de inundação do Solimões sobre o lago, conforme observado por Leite et al. (2006) ao afirmar que o lago do Catalão como a maioria dos lagos de várzea da região amazônica, aumenta ou diminui sua área de inundação em decorrência do nível dos rios adjacentes. Nesse sentido o lago possui como característica a influência do rio Solimões através de um curto canal, onde ocorre a conexão de ambos após os primeiros meses de aumento no nível das águas (de janeiro a abril). Entretanto dificilmente o lago se desconecta do rio Negro, salvo os períodos de secas mais intensas, quando a planície de inundação se resume a uma pequena área denominada "poção", mas mesmo assim continua ligando o lago ao rio Negro (LEITE et al., 2006).

O fluxo do lago próximo às moradias se apresentou lêntico nos dois períodos hidrológicos estudados (cheia e enchente), fato esse que provavelmente pode estar colaborando para possível à alta concentração de nutrientes na água, favorecendo a presença de macrófitas aquáticas em três pontos amostrais na enchente (2, 12, e 14) e em oito pontos amostrais na cheia (1, 2, 4, 5, 6, 9, 12 e 13). Além disso, a vegetação encontrada nas margens do lago varia de mata ciliar arbustiva à arbórea densa (RAMOS E WACHHOLZ, 2017).

As ações antrópicas sobre a planície de inundação que abriga o lago do Catalão em sua maioria não causam danos ambientais de grande porte, pois existe disponibilidade de área emersa somente durantes alguns meses do ano. Na cheia não se observou a presença de lixo doméstico na margem devido pouca ou nenhuma área de margem disponível devido ao nível alto das águas, 29,39 m (Porto de Manaus, 15 de julho de 2015), entretanto na enchente foi observado presença de lixo nas margens e na água.

\section{TEMPERATURA $\left({ }^{\circ} \mathrm{C}\right)$}

A temperatura da água oscilou entre 28,7 a $34,6^{\circ} \mathrm{C}$, com valor médio de $31,1 \pm 2,4^{\circ} \mathrm{C}$. Na enchente a temperatura apresentou-se entre 32,7 a $34,6^{\circ} \mathrm{C}$, sendo as maiores temperaturas encontradas nos pontos $3,6,7,8,9,10,12,13,14,15\left(\geq 33^{\circ} \mathrm{C}\right)$, a maioria desses se localiza próximo às margens do segundo furo, área com a maior densidade de moradias como foi observado nos pontos 12,13 e 14, situados próximo aos dois "Pesque-Pague" da comunidade, que apresentaram as maiores temperaturas da água $\left(34,6^{\circ} \mathrm{C}\right.$, $34,1^{\circ} \mathrm{C}$ e $34,1^{\circ} \mathrm{C}$, respectivamente) (RAMOS E WACHHOLZ, 2017).

No período de cheia a temperatura variou de 28,7 a $29,4^{\circ} \mathrm{C}$ (figura 6), onde as maiores temperaturas foram observadas nos pontos $9,11,13,15$ e $16\left(\geq 29^{\circ} \mathrm{C}\right)$. Cabe ressaltar que na cheia o maior valor $\left(29,4^{\circ} \mathrm{C}\right)$ foi observado no ponto 16 , amostrado no rio Negro. Nos pontos $9,11,13$ e 15 , localizados onde há maior número de moradia, obtiveram valor igual a $29,0^{\circ} \mathrm{C}$. Esses valores foram semelhantes aos encontrados em estudos realizados por Brito (2006) e Almeida (2008) em mesmo período hidrológico.

$\begin{array}{llllll}\text { Caminhos de Geografia } & \text { Uberlândia - MG } & \text { v. 21, n. 73 } & \text { Mar/2020 } & \text { p. } 98 \text { - } 115 & \text { Página } 107\end{array}$


Figura 6 - Temperatura da água nos pontos amostrais em dois períodos hidrológicos.

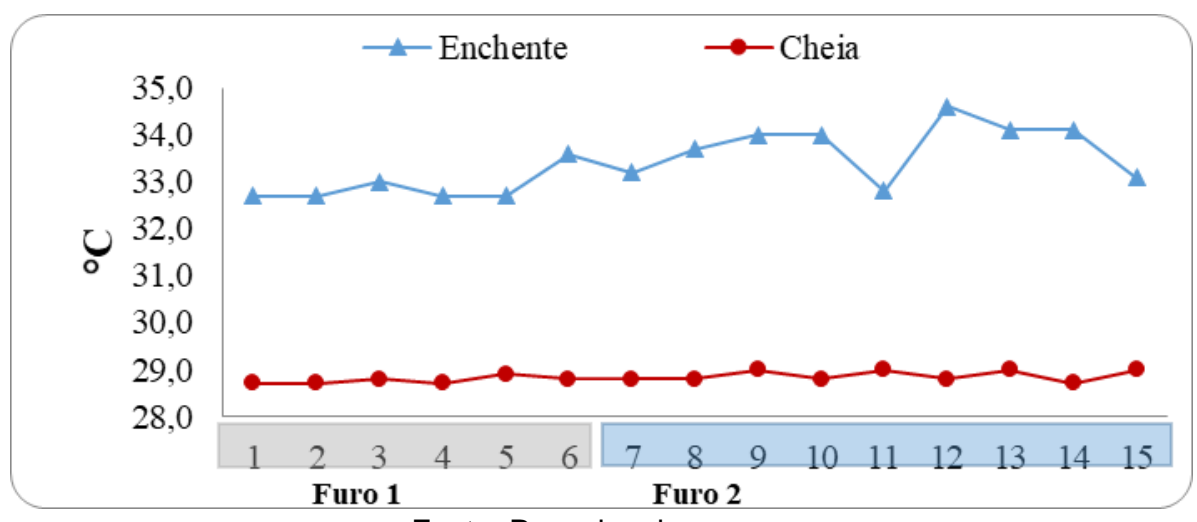

Fonte: Pesquisa de campo.

Elaboração: RAMOS, Marcos Fabricio Leal, 2015.

\section{TRANSPARÊNCIA (CM)}

Com relação à transparência do disco de Secchi, observou-se variação entre 40 e $73 \mathrm{~cm}$, com valor médio de $58 \pm 8,1 \mathrm{~cm}$ (figura 7). O período hidrológico de enchente foi aquele que apresentou os maiores e menores valores de transparência, variando entre 40 e $73 \mathrm{~cm}$, os pontos de 1 a 7 foram os que apresentaram os maiores valores $(\geq 65 \mathrm{~cm})$, logo é possível constatar que a transparência desses pontos está relacionada à área que possui menor número de moradias e menor tráfego de embarcações, esses se encontram no furo 1 , local que possui essas características.

Figura 7 - Transparência da água nos pontos amostrais em dois períodos hidrológicos.

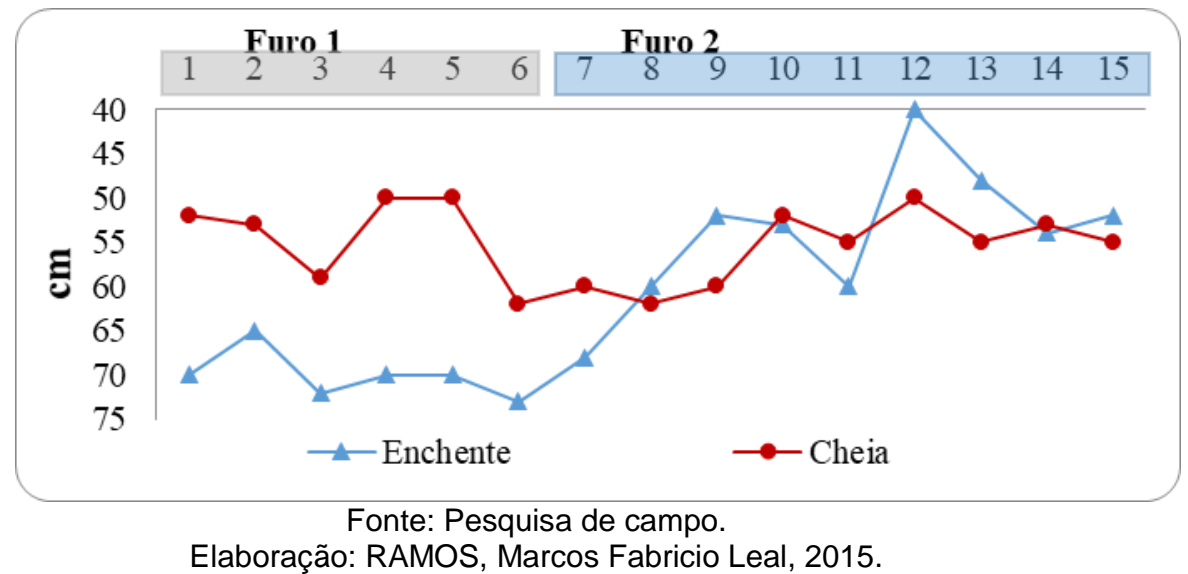

Segundo Sioli (1985) a Amazônia contempla rios de características diversas, que esses meios aquáticos se diferem também em sua coloração e transparência, onde três tipos se destacam os de águas brancas (turvas e barrentas), de águas pretas (com profundidades entre 90 a $150 \mathrm{~cm}$ de transparência) e de águas claras (de transparência cristalina e desprovida de excesso de material em suspensão).

$\mathrm{Na}$ cheia a transparência variou de 50 a $62 \mathrm{~cm}$, sendo os maiores valores obtidos nos pontos 3, 6, 7, 8, 9, 11,13 e $15(\geq 55 \mathrm{~cm})$. Essa redução da transparência está relacionada possivelmente a maior concentração de material em suspensão, devido à maior influência do rio Solimões. Esses resultados foram semelhantes aos encontrados por Brito (2006), no mesmo lago em mesmo período hidrológico.

Os valores padrões encontrados em lagos de várzea amazônicos apresentam transparência entre 18 a $180 \mathrm{~cm}$, enquanto lagos de águas pretas possui transparência superior, entre 120 a $240 \mathrm{~cm}$. Logo os valores encontrados mostram-se mais aproximados aos de várzea. Cabe ressaltar que no ponto 16 , amostrado no rio Negro, a transparência foi de $90 \mathrm{~cm}$ dentro do esperado para águas pretas (MARLIER, 1967; RIBEIRO, 1978; SANTOS, 1980; SCHMIDT, 1973 apud BRITO, 2006).

\begin{tabular}{llllll}
\hline Caminhos de Geografia & Uberlândia - MG & v. 21, n. 73 & Mar/2020 & p. $98-115$ & Página 108
\end{tabular}


Conforme Sioli (1985) e Almeida (2008) as águas do rio Negro possuem pH entre 3,8 a 5,5 e as águas brancas do Solimões entre 6,7 a 6,9. Nesse sentido os valores encontrados na enchente são superiores aos encontrados naturalmente nos dois tipos de água que influenciam o lago, logo esses valores se devem possivelmente a presença de lixo doméstico nas margens e do despejo de efluentes no lago e menor nível do rio, bem como maior aglomeração das moradias (RAMOS E WACHHOLZ, 2017).

$\mathrm{Na}$ cheia o $\mathrm{pH}$ variou entre 5,92 a 6,75 (figura 9), onde os maiores valores foram observados nos pontos $4,5,6,7,8,9,10$ e $11(>6,5)$. Esses se apresentaram superiores aos encontrados em águas pretas, mas dentro dos valores encontrados em águas brancas do rio Solimões. O menor valor encontrado nas duas amostragens foi obtido no ponto 12 (nesse período) com pH de 5,9.

Figura 9 - Valores de pH nos pontos amostrais em dois períodos hidrológicos.

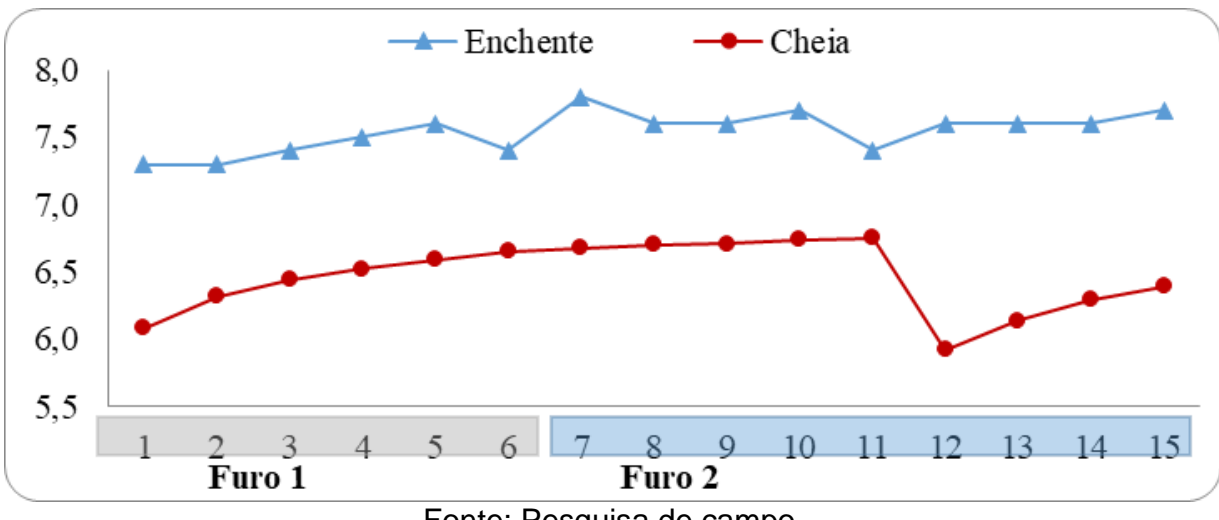

Fonte: Pesquisa de campo.

Elaboração: RAMOS, Marcos Fabricio Leal, 2015.

Essa diferença sazonal se deve provavelmente à influência do Solimões sobre o lago nesse período ser maior, fato este que também muda a coloração da água dando-lhe uma tonalidade barrenta, visto que ambos os furos do lago são afluídos pelo rio Negro e sofrem influência do Solimões no período de enchente e cheia. Esses valores encontrados na cheia aproximam-se dos observados por Brito (2006). Cabe ressaltar que o ponto 16 , amostrado no rio Negro, se apresentou com pH também superior ao esperado para águas pretas $(6,3)$.

\section{TURBIDEZ (NTU)}

A turbidez da água do Catalão apresentou variação entre 10,46 a 28,55 NTU (figura 10), com valor médio $19,2 \pm 4,8$ NTU. No período de enchente variou entre 10,46 a 20,67 NTU, onde os maiores valores foram encontrados nos pontos de 7 a 15, possivelmente relacionados ao maior despejo de efluentes (maior densidade de moradias) e tráfego de embarcações.

Figura 10 - Turbidez da água nos pontos amostrais em dois períodos hidrológicos.

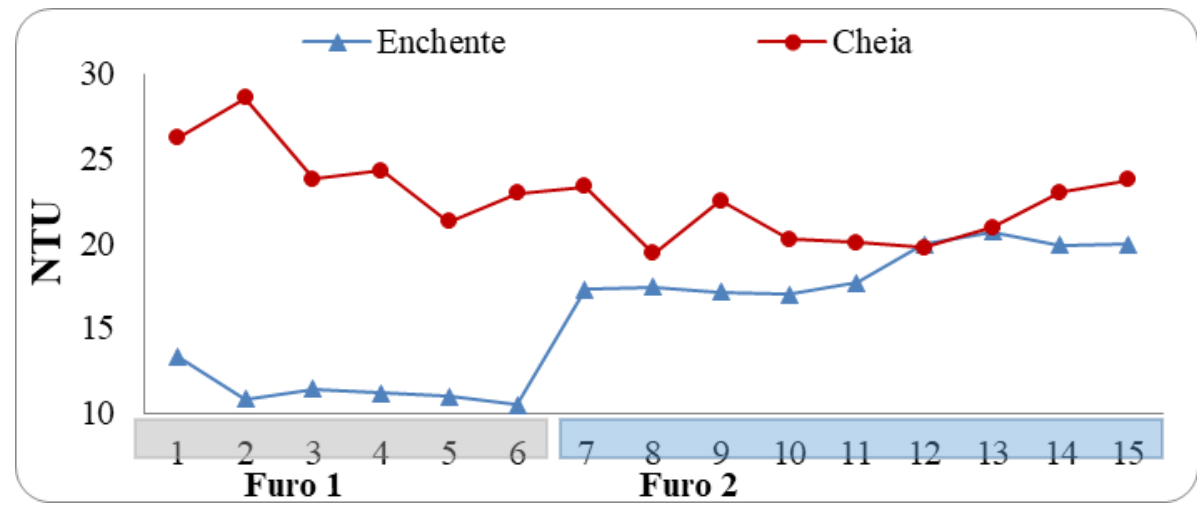

Fonte: Pesquisa de campo.

Elaboração: RAMOS, Marcos Fabricio Leal, 2015. 
$\mathrm{Na}$ cheia os valores de turbidez foram superiores, entre 19,42 a 28,55 NTU, onde os valores mais elevados foram encontrados nos pontos 1, 2, 3, 4, 7 e 15 ( $\geq 23$ NTU). O aumento da turbidez nesse período está relacionado à maior carga de material em suspensão, devido à influência do rio Solimões.

\section{OXIGÊNIO DISSOLVIDO (MG/L)}

$\mathrm{Na}$ água do lago observou-se variação de oxigênio dissolvido entre 2,4 (31,7\% de saturação) a 3,81 mg/L $(49,8 \%$ de saturação), com valor médio de $3,19 \pm 0,31 \mathrm{mg} / \mathrm{L}$. Este teor de oxigênio na água é relativamente baixo, pois todas as amostragens obtiveram valores abaixo de $50 \%$ de saturação. Na enchente, o oxigênio dissolvido variou de 2,8 (37,2\% de saturação) a 3,81 mg/L (49,8\% de saturação), sendo que os pontos 1 , $8,9,10,11,12,13,14$ e 15 ( $\geq 3,2 \mathrm{mg} / \mathrm{L})$ apresentaram os maiores valores, com saturação entre 42 a $50 \%$. Na cheia os valores de oxigenação da água foram inferiores ao período hidrológico anterior, pois variaram de 2,4 (31,7\% de saturação) a 3,64 mg/L (45\% de saturação), onde os maiores valores foram encontrados nos pontos $3,4,7,8,10,11,14$ e 15 ( $\geq 3,1 \mathrm{mg} / \mathrm{L}$ ) com saturação entre $39 \%$ a 45\%, conforme figura 11.

Figura 2 - Oxigênio dissolvido da água nos pontos amostrais em dois períodos hidrológicos.

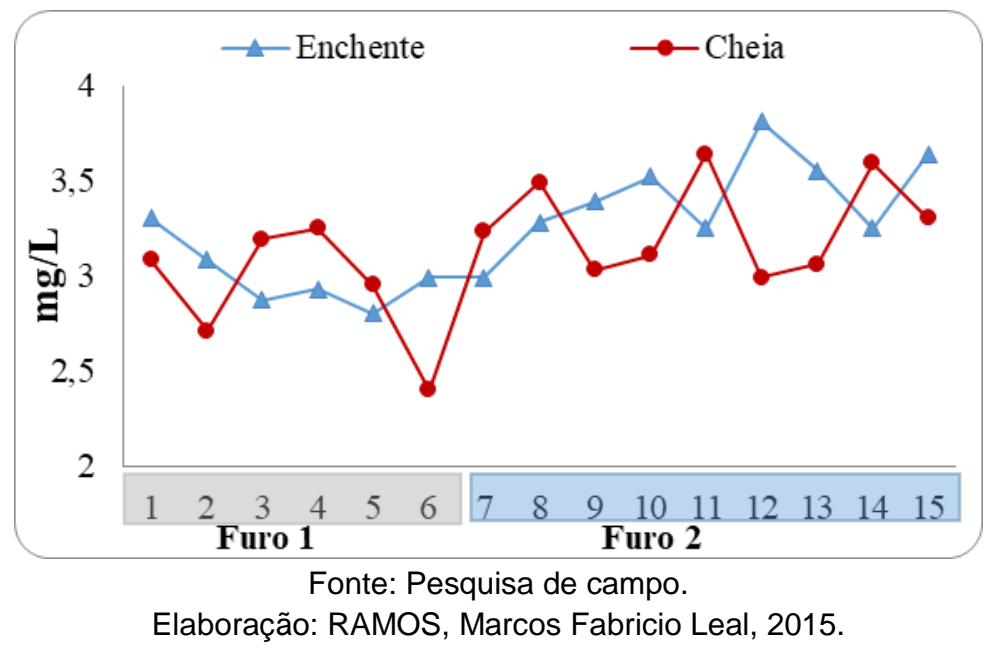

Os valores de oxigênio dissolvido na água do lago foram relativamente baixos, visto que em ambos os períodos hidrológicos não superou os $50 \%$ de saturação, sendo inferior a $4 \mathrm{mg} / \mathrm{L}$. O oxigênio dissolvido é um parâmetro de grande relevância na classificação das águas naturais, bem como na composição do índice de qualidade da água, sendo também um elemento essencial no metabolismo dos microrganismos aeróbios que habitam as águas naturais (CETESB, 2009). Nas águas naturais, o oxigênio é indispensável também para outros seres vivos, especialmente os peixes, onde a maioria das espécies não resiste a concentrações de oxigênio dissolvido na água inferiores a 4,0 mg/L (NETA PINTO et al., 2009). Desse modo, os baixos valores de oxigênio dissolvido da água do Lago do Catalão pode ser um indicativo de presença de carga orgânica na água.

\section{COLIFORMES FECAIS}

Em relação aos resultados da prova qualitativa para coliformes totais, dos 80 tubos analisados todos apresentaram coloração amarela, logo 100\% das amostras apresentaram contaminação, onde o ponto de coleta de água amostrado no rio Negro e os 15 que foram amostrados dentro da comunidade estavam contaminados. Esses 16 pontos analisados apresentaram valor superior a 8 NMP/100 mL para coliformes totais.

Os resultados para prova qualitativa de E. coli, principal indicador de contaminação fecal, demonstrou que $92,5 \%$ (74 tubos) estavam contaminados, pois emitiram fluorescência caracterizando prova positiva. Os pontos $1,2,4,5,6,7,8,9,10,12,13,14,15$ e 16 apresentaram valor superior a $8 \mathrm{NMP} / 100 \mathrm{~mL}$. Os pontos 3 e 11 apresentaram 2,6 e $8 \mathrm{NMP} / 100 \mathrm{~mL}$, respectivamente. Esses estão localizados em locais distintos, o terceiro está situado no primeiro furo, área com menor número de moradias, o ponto 11 encontra-se no final da comunidade, situado próximo à base de pesquisas do Instituto Nacional de

$\begin{array}{llllll}\text { Caminhos de Geografia } & \text { Uberlândia - MG } & \text { v. 21, n. 73 } & \text { Mar/2020 } & \text { p. } 98 \text { - } 115 & \text { Página } 111\end{array}$


Pesquisas da Amazônia (INPA) a montante do curso dos efluentes da comunidade. Portanto possuem menor influência dos efluentes lançados pela comunidade, fato esse que explica esses menores valores.

\section{VARIÁVEIS LIMNOLÓGICAS E LEGISLAÇÃO}

De acordo com os usos verificado com base nas informações recebidas da presidente a comunidade, e diante a legislação, o recurso hídrico da comunidade está apropriado segundo a variável oxigênio dissolvido somente para a navegação, assim está dentro dos padrões da classe IV. De acordo com pH, a água disposta em ambos os furos da comunidade, está adequada a todos os usos mencionados pelos moradores e enquadram-se satisfatoriamente em todas as classes. Perante a turbidez esse meio hídrico condiz com os parâmetros de qualidade estabelecidos pelas classes I e especial, desse modo conforme essa variável os usos adequados são: escovar os dentes, tomar banho, irrigação de hortaliças, natação e lazer (tabela 3).

Apesar disso, a variável coliformes fecais demonstrou que o uso da água do lago para o consumo humano após tratamento simplificado (aplicação de hipoclorito, fervura e filtração), evidenciado por $6 \%$ dos entrevistados, está inadequado, visto que os resultados obtidos nas análises foram superiores ao permitido segundo a portaria usada nesse estudo para determinar os padrões de qualidade para essa finalidade.

Tabela 3 - Variáveis e seu enquadramento segundo a legislação.

\begin{tabular}{|c|c|c|c|}
\hline Variável & Legislação & Resultado (mín/max) & Enquadramento* \\
\hline Oxigênio dissolvido & \multirow{3}{*}{ Conama №. 357/05 } & 2,4 a 3,61 mg/L & Classe IV \\
\hline $\mathrm{pH}$ & & 5,92 a 7,8 & $\begin{array}{c}\text { Classes I, II, III, IV e } \\
\text { especial }\end{array}$ \\
\hline Tubidez & & 10,46 a 28,55 NTU & Classe I e especial \\
\hline Coliformes totais & \multirow{2}{*}{$\begin{array}{l}\text { Portaria №. } \\
2.914 / 2011\end{array}$} & $100 \%$ das amotras & $\begin{array}{l}\text { Requer análise de } E \\
\text { coli }\end{array}$ \\
\hline $\begin{array}{l}\text { Coliformes fecais } \\
\text { (Escherichia colli) }\end{array}$ & & $92,5 \%$ da amostras & $\begin{array}{l}\text { Inadequado para o } \\
\text { consumo }\end{array}$ \\
\hline
\end{tabular}

Portanto a variável oxigênio dissolvido permite apenas usos de contato secundário (navegação), o pH contempla tanto usos de contato primário quanto secundário, pois mostram-se dentro dos valores esperados da resolução. A turbidez admitiu usos de contato primário, no entanto atendeu juntamente com a variável anterior aos parâmetros exigidos pela classe especial, essa que permite o consumo humano após desinfecção. Já a análise de coliformes fecais constata que a água do lago está fora dos padrões para o consumo, pois a porcentagem das amostras que comtemplavam contaminação por $\mathrm{E}$. coli foi significativa. Cabe mencionar que o valor estabelecido pela legislação para análises de coliformes deve ser obtido semanalmente, no entanto os resultados expressivos de contaminação obtidos em apenas uma amostragem demonstra claramente que a água do lago não comtempla os padrões de qualidade.

\section{CONSIDERAÇÕES FINAIS}

Portanto em relação às variáveis limnológicas e os maiores valores obtidos, a turbidez foi maior na cheia e apresentou menor variação no segundo furo, enquanto a transparência do disco de Secchi se mostrou superior na enchente, contudo apresentou também os menores valores nesse período. A variável temperatura teve menor variação na cheia e maiores valores na enchente, já o pH e condutividade elétrica, apresentaram diferenças acentuadas nos períodos hidrológicos. Enquanto a condutividade elétrica obteve maior média na cheia e significativa variação na enchente.

A determinação da amostragem em dois períodos hidrológicos, enchente e cheia, permitiu observar a influência do rio Negro e rio Solimões, nas características limnológicas do Lago do Catalão. Na enchente, os valores de turbidez $(15,67 \pm 3,86 \mathrm{NTU})$ e condutividade elétrica $(30,7 \pm 23,74 \mu \mathrm{S} / \mathrm{cm})$ foram menores que aqueles observados no período de cheia, enquanto a temperatura $\left(33,4 \pm 2,4^{\circ} \mathrm{C}\right)$ e a transparência

$\begin{array}{llllll}\text { Caminhos de Geografia } & \text { Uberlândia - MG } & \text { v. 21, n. 73 } & \text { Mar/2020 } & \text { p. } 98 \text { - } 115 & \text { Página } 112\end{array}$


$(60,4 \pm 10,2 \mathrm{~cm})$ foram maiores comparados à cheia. O oxigênio dissolvido $(3,19 \pm 0,31 \mathrm{mg} / \mathrm{L})$ teve baixos valores e pouca variação em ambos os períodos.

No entanto, os valores de $\mathrm{pH}(7 \pm 0,15)$ foram superiores a 7 (básico) no período da enchente, que está em desacordo com literatura quanto as águas pretas. Essa ocorrência pode estar relacionada a baixa circulação das águas nos furos e lago, mas é possível também denotar a influência da comunidade flutuante. Em maior nível de detalhe, pontos amostrais localizados em áreas com maior densidade de moradias apresentaram também maiores valores de turbidez e de temperatura e menor transparência.

Com base nos parâmetros de qualidade da água estabelecidos pela Resolução Conama (№. 357/2005), $\mathrm{pH}$ e turbidez enquadram o recurso hídrico para contato primário e secundário. No entanto, o oxigênio dissolvido permite uso apenas para navegação.

Considerando coliformes fecais de acordo a Portaria №. 2.914/2011, onde todas as amostras apresentaram contaminação por E. coli, a água torna-se imprópria ao consumo humano.

\section{AGRADECIMENTOS}

À Fundação de Amparo à Pesquisa do Estado do Amazonas (FAPEAM) pelo apoio financeiro à pesquisa.

\section{REFERÊNCIAS}

ALMEIDA, F. F. de; MELO, S. Considerações limnológicas sobre um lago da planície de inundação amazônica (lago Catalão-Estado do Amazonas, Brasil). Acta Scientiarum. Biological Sciences, v. 31, n. 4, p. 387-395, 2009. https://doi.org/10.4025/actascibiolsci.v31i4.4641.

ALMEIDA, F. F. Fitoplâncton de um lago de inundação amazônico (lago catalão, Amazonas-Brasil): estrutura da comunidade, flutuações espaciais e temporais. 2008. 79 f. Dissertação (Mestrado em Biologia Tropical e Recursos Naturais) - Universidade Federal do Amazonas, Instituto Nacional de Pesquisas da Amazônia, Manaus, 2008.

ASSIS, J. C. de. Água sob medida. AgroANALYSIS, v. 18, n. 3, p. 63-66. 1998.

ABNT - ASSOCIAÇÂO BRASILEIRA DE NORMAS TÈCNICAS -. NBR 9898: preservação e técnicas de amostragem de efluentes líquidos e corpos receptores - Procedimento. Rio de Janeiro, 1987. Disponível em: < http://licenciadorambiental.com.br/wp-content/uploads/2015/01/NBR-9.898-Coletade-Amostras.pdf>. Acesso em: 22 de jun. de 2014.

BITTENCOURT, M. M.; AMADIO, S. A. Proposta para identificação rápida dos períodos hidrológicos em áreas de várzea do rio Solimões-Amazonas nas proximidades de Manaus. Acta Amazônica, v. 37, n. 2, p. 303-308, 2007. https://doi.org/10.1590/S0044-59672007000200019

BLEICH, M. E.; PIEDADE , M. T. F.; KNOPKI, P. B.; CASTRO, N. G. D. de; JATI, S. R.; SOUSA, R. N. de. Influência das condições do habitat sobre a estrutura de herbáceas aquáticas na região do Lago Catalão, Manaus, AM. Acta Amazônica, v. 44, n. 4, p.481-490, 2014. https://doi.org/10.1590/1809$\underline{4392201400023}$

BORSOI, Z. M. F.; TORRES, S. D. A. A política de recursos hídricos no Brasil. Revista do BNDES, v. 4, n. 8, p. 143-166, 1997.

BRASIL. Ministério da Saúde. Portaria № 2.914, de 12 de dezembro de 2011: Dispõe sobre os procedimentos de controle e de vigilância da qualidade da água para consumo humano e seu padrão de potabilidade, 2011. 15 p. Disponível em: < http://www.cvs.saude.sp.gov.br/zip/Portaria_MS_291411.pdf >. Acesso em: 12 fev. 2018.

BRASIL. Ministério do Meio Ambiente. Conselho Nacional do Meio Ambiente (CONAMA). Resolução no 357 , de 17 de março de 2005. Dispõe sobre a classificação dos corpos de água e diretrizes ambientais para o seu enquadramento, bem como estabelece as condições e padrões de lançamento de efluentes, e dá outras providências. Disponível em: <http://www.mma.gov.br/port/conama/legiabre.cfm?codlegi=459>. Acesso em: 21 jan. 2018.

BRITO, J. G de. Influência do pulso de inundação sobre variáveis limnológicas de um lago de várzea da Amazônia Central, lago Catalão. 2006. 191 f. Dissertação (Mestrado em Biologia Tropical e Recursos Naturais) - Universidade Federal do Amazonas, Instituto Nacional de Pesquisas da Amazônia, Manaus, 2006. 
CETESB - Companhia Ambiental do Estado de São Paulo. Guia nacional de coleta e preservação de amostras: água, sedimento, comunidades aquáticas e efluentes líquidos / Companhia Ambiental do Estado de São Paulo; Organizadores: Carlos Jesus Brandão ... [et al.]. -- São Paulo: CETESB; Brasília: ANA, 2011. Disponível em: < http://laboratorios.cetesb.sp.gov.br/wpcontent/uploads/sites/47/2013/11/guia-nacional-coleta-2012.pdf>. Acesso em: 15 jan. 2017.

CETESB - Companhia Ambiental do Estado de São Paulo. Significado ambiental e sanitário das variáveis de qualidade das águas e dos sedimentos e metodologias analíticas e de amostragem. São Paulo, 2009, 43 p. Disponível em: <http://cetesb.sp.gov.br/aguas-interiores/wpcontent/uploads/sites/32/2013/11/variaveis.pdf>. Acesso em: nov. 2017.

INSTITUTO TRATA BRASIL. Situação Saneamento no Brasil, 2017. Disponível em: http://www.tratabrasil.org.br/saneamento-no-brasil. Acesso em: 18/11/2018.

LEITE, R. G.; SILVA, J. V. V. da; FREITAS, C. E. Abundância e distribuição das larvas de peixes no Lago Catalão e no encontro dos rios Solimões e Negro, Amazonas, Brasil. Acta Amazônica, v. 36, n. 4, p. 557-562, 2006. https://doi.org/10.1590/S0044-59672006000400018.

LIBÂNIO, P. A. C.; CHERNICHARO, C. A. de L.; NASCIMENTO, N. de O. A dimensão da qualidade de água: avaliação da relação entre indicadores sociais, de disponibilidade hídrica, de saneamento e de saúde pública. Engenharia Sanitária e Ambiental, v. 10, n. 3, p. 219-228, 2005. https://doi.org/10.1590/S1413-41522005000300006.

LIMA, J. A. de; RODRIGUES, M. V.; ANTONIO, M. A. P. M. de.; JANZEN, J. G.; MARCHETTO, M. Potencial da economia de água potável pelo uso de água pluvial: análise de 40 cidades da Amazônia. Engenharia Sanitária e Ambiental, v. 16, n. 3, p. 291-298, 2011. https://doi.org/10.1590/S141341522011000300012.

MACHADO, C. J. S. Recursos hídricos e cidadania no Brasil: limites, alternativas e desafios. Ambiente e Sociedade, v. 6, n. 2, p. 121-136, 2003 . https://doi.org/10.1590/S1414753X2003000300008.

MARENGO, J. A. Água e mudanças climáticas. Estudos avançados, v. 22, n. 63, p. 83, 2008. https://doi.org/10.1590/S0103-40142008000200006.

MELO, E. G. F.; SILVA, M. S. R. da; MIRANDA, S. A. F. Influência antrópica sobre águas de igarapés na cidade de Manaus-Amazonas. Caminhos de Geografia, v. 5, n. 16, p. 40-47, 2005.

MORAES, R. Na planície Amazônica. 2. ed. Rio de Janeiro: Conquista, 1960. 229 p.

NETA PINTO, A. G.; HORBE, A. M. C.; SILVA, M. do S. R. da; MIRANDA, S. A. F.; PASCOALOTO, D.; SANTOS, H. M. da C. Efeitos da ação antrópica sobre a hidrogeoquímica do rio Negro na orla de Manaus/AM. Acta amazônica, v. 39, n. 3, p. 627-638, 2009. https://doi.org/10.1590/S0044$\underline{59672009000300018 .}$.

PEIXOTO FILHO, A. C.; BONDAROVSKY, S. H. Água, bem econômico e de domínio público. Revista CEJ, v. 4, n. 12, p. 13-16, 2000.

RAMOS, Marcos Fabricio Leal; WACHHOLZ, Flávio. Caracterização da temperatura, pH e condutividade elétrica das águas superficiais na comunidade flutuante do Catalão, Iranduba Amazonas. In: João C. A. da Silva Neto; Natacha C. R. Aleixo; Leonice S. Dias. (Org.). Dinâmicas Socioambientais na Amazônia Brasileira. 1ed.Tupã SP: ANAP, 2017, v. 1, p. 46-59.

SANTOS, J. Zoom na região hidrográfica amazônica: Os rios da Amazônia apresentam características físicas e químicas heterogêneas, com algumas peculiaridades que dificultam a gestão destes recursos, diante à legislação vigente (resolução Conama 357/2005). Ciência para todos, Manaus: INPA, n. 11, p. 32-41, 2014.

SARRI, Rodrigo Ferreira. Proposta de tambor séptico biodigestor para região de várzea Amazônica e sua contribuição para o tratamento de esgoto na conservação dos recursos hídricos. 2018. 107 f. Dissertação (Mestrado em Gestão e Regulação de Recursos Hídricos) - Universidade do Estado do Amazonas, Manaus, 2018.

SIOLI, H. Amazônia: fundamentos da ecologia da maior região de florestas tropicais. Petrópolis: Vozes, 1985. $72 \mathrm{p}$.

TUCCI, C. E. M. Águas urbanas. Estudos avançados, v. 22, n. 63, p. 97-112, 2008. https://doi.org/10.1590/S0103-40142008000200007.

Caminhos de Geografia Uberlândia - MG v. 21, n. 73

Mar/2020 p. $98-115 \quad$ Página 114


TUCCI, C. E. M. Gerenciamento da drenagem urbana. RBRH - Revista Brasileira de Recursos Hídricos, v. 7, n. 1, p. 5-27, 2001. https://doi.org/10.21168/rbrh.v7n1.p5-27.

TUNDISI, J. G. Ciclo hidrológico e gerenciamento integrado. Ciência e Cultura, v. 55, n. 4, p. 31-33, 2003.

TUNDISI, J. G.; MATSUMURA-TUNDISI, T. Limnologia. 1. ed. São Paulo: Oficina de Textos, 2008. $631 \mathrm{p}$.

Recebido em: 11/03/2018

Aceito para publicação em: 13/11/2019 